FARIA P., DUARTE P., BARBOSA D., FERREIRA I. (2017), New composite of natural hydraulic lime mortar with graphene oxide.

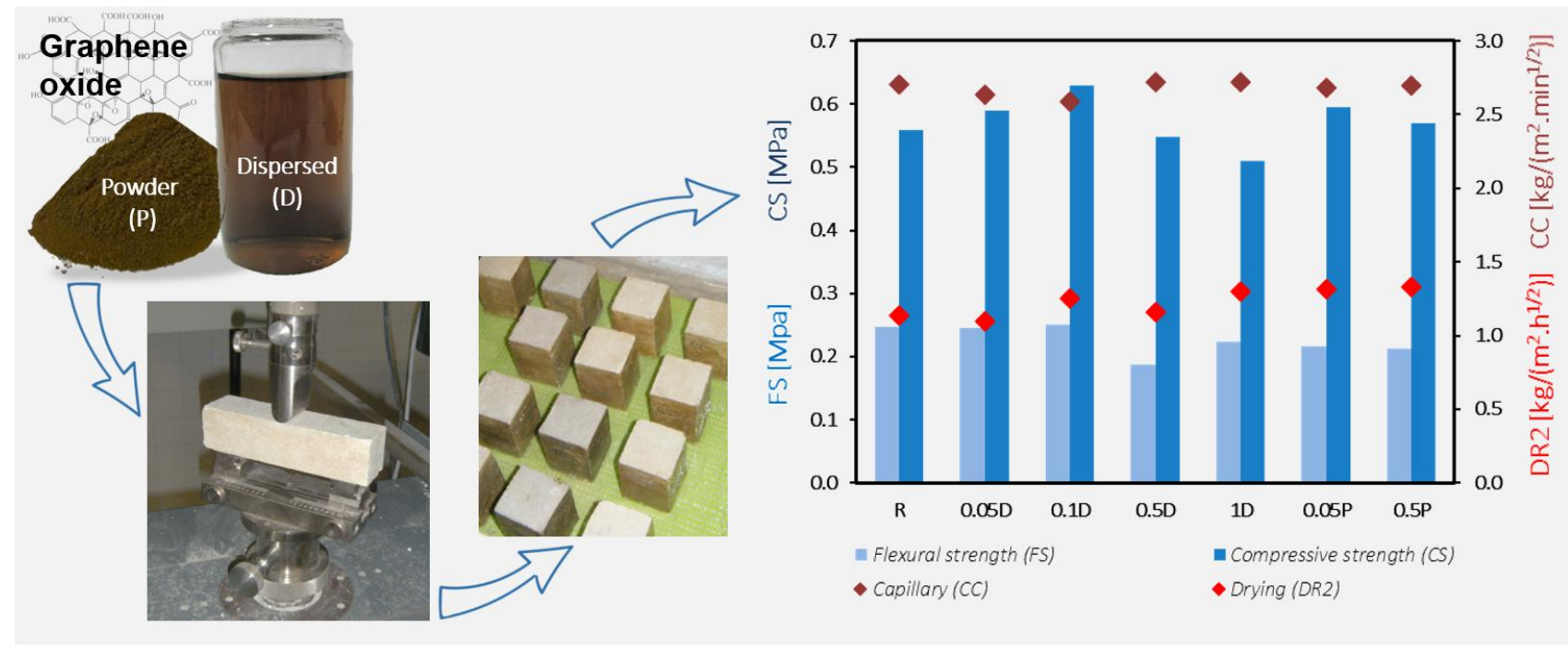

Highlights

The influence of graphene oxide (GO) addition on a NHL mortar was studied

Better results were obtained with water dispersed GO in comparison to powder GO

Mineralogical testing did not identify the GO compounds on mortars

GO in 0.05 and 0.1 wt.\% lead to a slight improvement of mechanical characteristics

GO in 0.1 wt.\% provided better durability to liquid or vapour water action

\title{
New composite of natural hydraulic lime mortar with graphene oxide
}

Paulina Faria ${ }^{1}$, Paulo Duarte ${ }^{2}$, Davide Barbosa ${ }^{3}$, Isabel Ferreira ${ }^{4}$

1 CERIS and Department of Civil Engineering, Universidade NOVA de Lisboa, Portugal, paulina.faria@fct.unl.pt

2 LAQV - REQUIMTE, Department of Chemistry, and CENIMAT/I3N, Department of Materials Science, Universidade NOVA de Lisboa, Portugal, pauloduarte@fct.unl.pt

${ }^{3}$ Department of Civil Engineering, Universidade NOVA de Lisboa, Portugal, df.barbosa@campus.fct.unl.pt

${ }^{4}$ CENIMAT/I3N and UNINOVA, Department of Materials Science, Universidade NOVA de Lisboa, Portugal, imf@fct.unl.pt

Corresponding Author: * paulina.faria@fct.unl.pt

Keywords: Graphene oxide; natural hydraulic lime; mortar; microstructure; mechanical property; physical property 


\section{Abstract}

Recent studies show the incorporation of graphene oxide (GO) in cement composites. But these composites are frequently incompatible with original materials for building rehabilitation. To overcome this limitation, natural hydraulic lime mortars were used as matrix, and the influence of GO percentage and type of mixing was investigated. The influence on the microstructure, mechanical and physical properties was assessed. The best results were obtained with dispersed $\mathrm{GO}$ at concentrations of $0.05 \%$ and $0.1 \%$. A slight improvement of mechanical and physical characteristics was achieved. This could lead to new mortars with improved properties that can be used for building rehabilitation.

\section{Introduction}

In recent years the development of new materials at nanoscale has undergone great evolution. These new nanomaterials have the potential to be applied in several fields, including the construction industry. Among the many types of nanomaterials studied for potential application in construction carbon-based materials are ones the most studied particularly carbon nanotubes (CNT), carbon nanofibers (CNF) and graphene oxide (GO). Recent studies have shown that small amounts of carbon nanomaterial contribute to the increase of mechanical properties of cementitious composites, being applied as a reinforced material to cement matrix in pastes and mortars, differing by the inclusion of sand (see Table 1). Notably, GO has attracted enormous attention due its high specific surface area, high strength, flexibility and hydrophilic character [1,2].

Table 1. Mechanical properties of cement composites with carbon-based nanomaterial

\begin{tabular}{|c|c|c|c|c|}
\hline Ref & Matrix & $\begin{array}{l}\text { Nanomaterial } \\
\text { [wt.\% cement] }\end{array}$ & Dispersion method & $\begin{array}{c}\text { Results } \\
\text { (improvement compared to the reference } \\
\text { composite) }\end{array}$ \\
\hline$[5]$ & Paste & $\begin{array}{c}\text { MWCNT } \\
(0.15 / 0.045)\end{array}$ & Sonication with polyacrylic acid & $\begin{array}{l}\text { Flexural strength: } 16 \% \text { (with } 0.15 \text { wt.\%) } \\
\text { Compressive strength: } 50 \% \text { (with } 0.045 \\
\text { wt.\%) }\end{array}$ \\
\hline$[6]$ & Paste & $\begin{array}{l}\text { MWCNT } \\
(0.2 / 0.1)\end{array}$ & $\begin{array}{l}\text { Ultrasonication, centrifugation and } \\
\text { sonication with TNWDIS }\end{array}$ & $\begin{array}{l}\text { Flexural strength: } 40 \% \text { (with } 0.2 \text { wt.\%) } \\
\text { Compressive strength: } 15 \% \text { (with } 0.1 \\
\text { wt. \%) }\end{array}$ \\
\hline [9] & Mortar & MWCNT $(0.5)$ & $\begin{array}{l}\text { Sonication and carboxylation with } \\
\text { sulfuric and nitric acid }\end{array}$ & $\begin{array}{l}\text { Flexural strength: } 25 \% \\
\text { Compressive strength: } 19 \%\end{array}$ \\
\hline$[10]$ & Mortar & CNF (2.0) & Sonication & $\begin{array}{l}\text { Flexural strength: } 11 \% \\
\text { Compressive strength: } 10 \%\end{array}$ \\
\hline$[1]$ & Paste & GO (0.04/0.06) & Sonication & $\begin{array}{l}\text { Flexural strength: } 67 \% \text { (with } 0.04 \text { wt.\%) } \\
\text { Compressive strength: 59\% (with } 0.06 \\
\text { wt.\%) }\end{array}$ \\
\hline
\end{tabular}




\begin{tabular}{|c|c|c|c|l|}
\hline [3] & Paste & GO (0.08) & $\begin{array}{c}\text { Sonication with silica fume and } \\
\text { centrifugation }\end{array}$ & $\begin{array}{l}\text { Flexural strength: } 30 \% \\
\text { Compressive strength: } 12 \%\end{array}$ \\
\hline [4] & Paste & GO (0.05) & Ultrasonication & Compressive strength: $19 \%$ \\
\hline [11] & Mortar & GO (0.05) & Supplied already dispersed & $\begin{array}{l}\text { Flexural strength: } 71 \% \\
\text { Compressive strength: } 24 \%\end{array}$ \\
\hline$[12]$ & Mortar & GO (0.4) & $\begin{array}{c}\text { Sonication and electrophoretic } \\
\text { deposition (in carbon fibre) }\end{array}$ & $\begin{array}{l}\text { Flexural strength: } 6 \% \\
\text { Compressive strength: } 5 \%\end{array}$ \\
\hline$[8]$ & Mortar & GO (0.03) & Ultrasonication & Flexural strength: $78.6 \%$ \\
\hline$[7]$ & Mortar & GO (2.0) & Ultrasonication & Flexural strength: $24.7 \%$ \\
\hline
\end{tabular}

In prior studies very small amounts of GO has been added to cement pastes (from 0.04 to 0.08 wt.\%) with remarkable enhancement in both flexural and compressive strengths, up to $67 \%$ and $59 \%$ respectively $[1,3,4]$, when compared to cementitious pastes containing multi-walled carbon nanotubes (MWCNT) $[5,6]$. An increase in the mechanical properties of hardened cement mortars incorporating GO nanosheets has also been observed. The most significant improvements in mortars occur with the addition of GO in small amounts (0.03 wt.\% to $0.05 \mathrm{wt}$ ). Adding MWCNT or CNF lead to minor improvements in the mechanical properties of cementitious mortars [7-12].

Mohammed et al. [2] explored the impact of GO on other properties of cement. The researchers proved that the addition of $\mathrm{GO}$ to cement composite can improve the cement matrix transport properties by performing water sorptivity and chloride penetration tests. But studies have been mainly performed only with cementbased composites and these are frequently incompatible with original materials of existing and historic buildings.

Natural hydraulic limes (NHL) are binders in conformity with the EN 459-1:2010 [13]. This type of binder is obtained by firing marly limestone at a temperature similar to the one used to produce air lime, and consists of calcium silicates, calcium aluminates and calcium hydroxide. It is classified as a binder with hydraulic properties [13], having not only a hydraulic curing but also an aerial curing obtained by carbonation with atmospheric carbon dioxide. This double type of curing can be very beneficial for a variety of applications, particularly in conservation or rehabilitation interventions of existent and historic buildings [14,15]. There are three different classes of $\mathrm{NHL}$, each one with a minimal amount of $\mathrm{Ca}(\mathrm{OH})_{2}$ [13]. $\mathrm{NHL}$ composites are suitable and compatible with different types of supports, being used as grouts to consolidate thick old masonries [16], as renders and plasters [15].

For these reasons, the incorporation of GO on natural hydraulic lime mortars was investigated in this study for the first time, driven by the demand for the enhancement of the properties of the traditional materials used in the rehabilitation of buildings. 


\section{Experimental details}

\subsection{Materials}

The mortars produced in this research are composed by lime, sand, graphene oxide and water. The binder used was a natural hydraulic lime NHL3.5 produced by SECIL Argamassas in accordance with EN 4591:2010 [13]. Its chemical composition determined by X-ray fluorescence and mineralogical phases determined by XRD were assessed elsewhere [15]. The chemical composition is shown in Table 2. The main mineralogical phases present are calcite $(\mathrm{C})$, portlandite $(\mathrm{CH})$ and larnite $(\mathrm{C} 2 \mathrm{~S})$. Minor phases detected include quartz (SiO2), tricalcium aluminate (C3A) and bassanite (CaSO4 0.5H2O) [15]. A fine siliceous sand, with particle size distribution given in Figure 1, was used.

Table 2. Chemical composition of natural hydraulic lime NHL3.5 [15]

\begin{tabular}{|c|c|c|c|c|c|c|c|c|c|c|c|}
\hline \multicolumn{10}{|c|}{ Content [wt.\%] } \\
\hline $\mathrm{SiO}_{2}$ & $\mathrm{Al}_{2} \mathrm{O}_{3}$ & $\mathrm{Fe}_{2} \mathrm{O}_{3}$ & $\mathrm{MnO}$ & $\mathrm{MgO}$ & $\mathrm{Na}_{2} \mathrm{O}$ & $\mathrm{K}_{2} \mathrm{O}$ & $\mathrm{TiO}_{2}$ & $\mathrm{P}_{2} \mathrm{O}_{5}$ & $\mathrm{SO}_{3}$ & $\mathrm{CaO}$ & $\begin{array}{c}\text { Loss on } \\
\text { ignition }\end{array}$ \\
\hline 5.70 & 1.84 & 1.22 & 0.02 & 1.00 & 0.08 & 0.49 & 0.14 & 0.03 & 1.00 & 62.00 & 26.00 \\
\hline
\end{tabular}

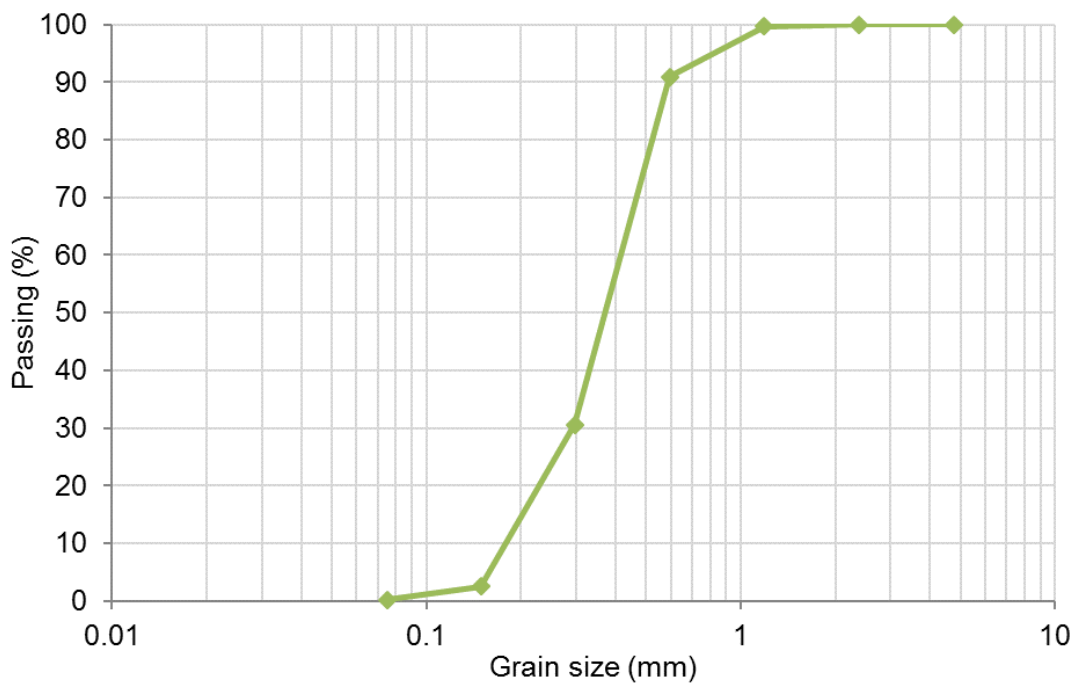

Figure 1. Particle size distribution of fine siliceous sand

The loose bulk density of the lime and sand are $0.709 \mathrm{~g} / \mathrm{cm}^{3}$ and $1.46 \mathrm{~g} / \mathrm{cm}^{3}$, respectively, assessed by the mass of the material filling a known volume. GO was synthesized from pyrolytic graphite (a waste of the high temperature furnaces of the metallurgy industry) using the modified Hummers method as described elsewhere [17]. Briefly, $4 \mathrm{~g}$ of pyrolytic graphite powder were mixed together with $2 \mathrm{~g}$ of sodium nitrate in $92 \mathrm{~mL}$ of sulphuric acid. After 1 hour, $12 \mathrm{~g}$ of potassium permanganate were added slowly and stirred for 12 hours 
before the addition of $2 \mathrm{~L}$ of water and $20 \mathrm{~mL}$ of hydrogen peroxide. The suspension was washed with hydrochloric acid and water by filtration. The final GO powder was obtained by freeze drying for 48 hours (Figure 2a).
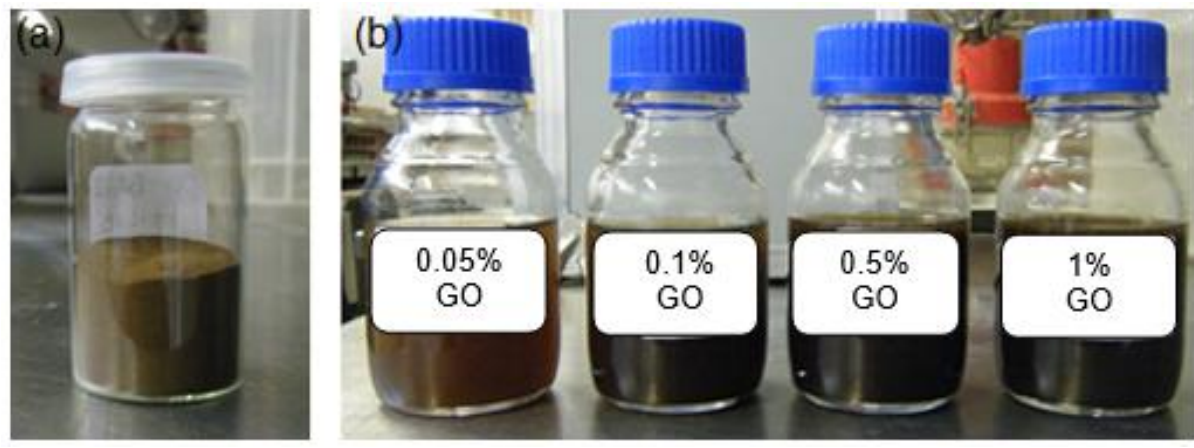

Figure 2. a) GO in powder and b) Dispersed GO by sonication

\subsection{Preparation of $\mathrm{GO}$ and mortars}

Three types of NHL3.5 mortars have been prepared: reference mortar (R), without nanomaterial; mortar containing aqueous dispersion of GO (D); mortar with powder GO (P). The ratio of binder:aggregate was 1:3, in volume, corresponding to a ratio of 1:6.2 in weight and the water/binder ratio was 1.27 . The content of binder, aggregate and water were held constant, varying only the amount of nanomaterial. For the D samples, four percentages of $\mathrm{GO}(0.05 \%, 0.1 \%, 0.5 \%$ and $1 \%$ - weight of $\mathrm{NHL})$ were prepared, dispersed in $200 \mathrm{ml}$ of deionized water and sonicated for $20 \mathrm{~min}$ with $10 \mathrm{~min}$ ON/10 min OFF cycles to create stable dispersions, and are shown in Figure 2b). For the $\mathrm{P}$ samples, $\mathrm{GO}$ in powder was directly incorporated with the mortar dry components at two different percentages, $0.05 \%$ and $0.5 \%$ by weight of $\mathrm{NHL}$. The identification of mortar mixes and its composition are presented in Table 3.

Table 3. Mortars identification, composition and consistency

\begin{tabular}{|c|c|c|c|c|}
\hline \multicolumn{2}{|c|}{ Mortar* } & $\begin{array}{c}\text { GO } \\
{[\%]}\end{array}$ & $\begin{array}{c}\text { GO } \\
{[\mathrm{mg}]}\end{array}$ & $\begin{array}{c}\text { Consistency } \\
{[\mathrm{mm}]}\end{array}$ \\
\hline Without GO & $\mathrm{R}$ & - & - & 166 \\
\hline \multirow{3}{*}{$\begin{array}{c}\text { Dispersed } \\
\text { GO }\end{array}$} & $0.05 \mathrm{D}$ & 0.05 & 149 & 161 \\
\cline { 2 - 5 } & $0.1 \mathrm{D}$ & 0.1 & 299 & 169 \\
\cline { 2 - 5 } & $0.5 \mathrm{D}$ & 0.5 & 1494 & 162 \\
\cline { 2 - 5 } & $1 \mathrm{D}$ & 1 & 2989 & 154 \\
\hline \multirow{2}{*}{$\begin{array}{c}\text { GO in } \\
\text { powder }\end{array}$} & $0.05 \mathrm{P}$ & 0.05 & 149 & 161 \\
\cline { 2 - 5 } & $0.5 \mathrm{P}$ & 0.5 & 1494 & 170 \\
\hline
\end{tabular}

* Each of the mortar mixes had $298.9 \mathrm{~g}$ of $\mathrm{NHL}$ and $1846.4 \mathrm{~g}$ of sand 


\subsection{Specimen preparations and curing}

The production of the mortars was based on EN 1015-2:1998/A1:2006 [18]. First of all, dry constituents (binder and aggregate) were manually homogenized and then placed in the rotary mixer container. The equipment was operated for 150 seconds at low speed of rotation, stopped for 30 seconds to scrape the mortar on the container edges and finished with an additional 30 seconds of mechanical mixing. The mixing water was added in the first 20 seconds of mechanical mixing. In mortars with addition of dispersed GO, the container containing dispersion was stirred and then poured into a graduated cylinder, adding water to make the amount initially defined of mixing water. In mortars containing GO on powder, it was directly added to the homogenized the dry constituents.

The mortars were then cast in two layers, each one with mechanical compaction trough vibration table, into metallic prismatic moulds of $40 \mathrm{~mm} \times 40 \mathrm{~mm} \times 160 \mathrm{~mm}$. The moulds with the specimen were conditioned inside polyethylene bags for initial curing with high relative humidity. At the second day of curing mortar specimen were demoulded and continued inside the bags until completing 7 days. Afterwards the specimens were cured in a conditioned room with $20 \pm 2^{\circ} \mathrm{C}$ and $65 \pm 5 \% \mathrm{HR}$ and tested at the age of 28 days.

\subsection{Testing procedures}

\subsubsection{Flow table consistency and general remarks}

The consistency of fresh mortars was determined by flow table test based on EN 1015-3:1999 [19]. All the test on hardened mortars were performed at 28 days of age. Except when mentioned, all the results are an average of at least three tests. Standard deviation is presented whenever possible.

\subsubsection{Fourier Transform Infrared Spectroscopy, X-ray Diffraction and Scanning Electron Microscopy}

Fourier transform infrared spectroscopy (FTIR) was carried out using a Thermo-Nicolet 6700 spectrophotometer from Thermo Electron Corporation in attenuated total reflection mode (ATR). The spectra were recorded based on 32 scans, performed in the mid-infrared range $\left(500-4000 \mathrm{~cm}^{-1}\right)$ adopting a resolution of $4 \mathrm{~cm}^{-1}$.

The structural analysis of the samples was performed by X-ray diffraction (XRD) using a X'Pert Pro X-ray diffractometer from PANalytical, equipped with an X'Celerator detector, in a Bragg-Brentano geometry with CuKa line radiation $(\lambda=1.5406 \AA)$. The $2 \theta$ scans were performed from $10^{\circ}$ to $60^{\circ}$, with a step size of $0.001^{\circ}$. 
Both these tests were performed with the GO and the mortars. Mortars were ground to powder and only one sample of each was tested.

The morphology of GO was analysed by Scanning Electron Microscopy (SEM) using a Carl Zeiss AURIGA Crossbeam SEM- FIB (Oberkochen, Germany).

\subsubsection{Mechanical strength of hardened mortar}

Flexural strength (FS) and compressive strength (CS) tests were conducted in accordance with EN 101511:1999 [20]. The flexural action was imposed using a three-point flexure testing apparatus, ZWICK Z050, with a $2 \mathrm{kN}$ load cell. For the compressive test the action was imposed in an area of $40 \mathrm{~mm} \times 40 \mathrm{~mm}$ in the same apparatus, but with a load cell of $50 \mathrm{kN}$.

\subsubsection{Porosity}

Samples with dimensions $20 \mathrm{~mm} \times 40 \mathrm{~mm} \times 40 \mathrm{~mm}$ resulting from the prismatic specimen were used for the determination of open porosity and hardened bulk density by hydrostatic method, based on EN 1936:2008 [21]. The mortar samples were previously placed in an oven at $60 \pm 5^{\circ} \mathrm{C}$ for a minimum of 24 hours for mass stabilization. The samples were kept dry and under vacuum for 24 hours on a desiccator. Then water was slowly introduced into the desiccator until all samples are fully immersed and maintained under vacuum for another 24 hours and, finally, the samples were kept immersed but at ambiance pressure for more 24 hours. After this process they were hydrostatically and saturated weighed.

For mercury intrusion porosimetry (MIP) a Micromeritics Autopore IV was used for determination of volume and distribution of pores by applying different levels of pressure to a sample immersed in mercury: low pressures ranging from $0.01 \mathrm{MPa}$ to $0.21 \mathrm{MPa}$, followed by high-pressures from $0.28 \mathrm{MPa}$ to $206.84 \mathrm{MPa}$ : The required pressure to intrude mercury into the samples' pores is proportional to the size of pores. The samples used in this test were first prepared in order to occupy a great part of the MIP penetrometer $\left(5 \mathrm{~cm}^{3}\right)$ and placed in a ventilated oven at $40^{\circ} \mathrm{C}$ until reach constant mass. One sample of each mortar was tested.

\subsubsection{Water absorption by capillarity and drying tests}

The water absorption by capillarity and drying tests were performed with a half sample resulting from the specimen tested for the flexural test. Capillary absorption test was based on EN 1015-18:2002 [22] and EN 15801:2009 [23]. First, the specimens were placed in an oven at $60 \pm 5^{\circ} \mathrm{C}$ for about 48 hours until constant mass was reached. An epoxy resin was used to seal the side surfaces of the specimen. The capillary water absorption curves, with the water absorption by contact area with water function of the square root of time, are determined. Based on these curves the capillary coefficient (CC) is calculated by the slope of the initial 
segment of the curve, and the asymptotic value (AV) represents the total amount of absorbed water by contact area.

The drying test was started when the water absorption test by capillarity lead samples to saturation. But previously the base of the specimens was wrapped in cling film (with a rubber band) so that there was a unidirectional drying process, only by the top free section. This test was based on EN 16322:2013 [24]. The drying curves are determined by the residual amount of water present in the specimen (M) reported as a function of time (showing the first phase of drying) or the square root of time (showing the second phase of draying). The drying rates of the two initial phases are defined: DR1 and DR2, corresponding to the first or the second drying phases, respectively, are determinate by the negative slopes of the linear parts of the drying curves. The drying index (DI) is also determined, corresponding to a weighted ratio of the area of the drying curve function of time and its total area.

\section{Experimental results and analysis}

\subsection{SEM images, FTIR spectra and XRD patterns}

The morphology of GO powder was investigated by SEM (Figure 3). The average particle size of GO is about $6 \mu \mathrm{m}$ (Figure 3a). With a higher magnification, it is possible to see the GO sheets that form these particles (Figure 3b), showing the successful exfoliation of the pyrolytic graphite by modified Hummers method.

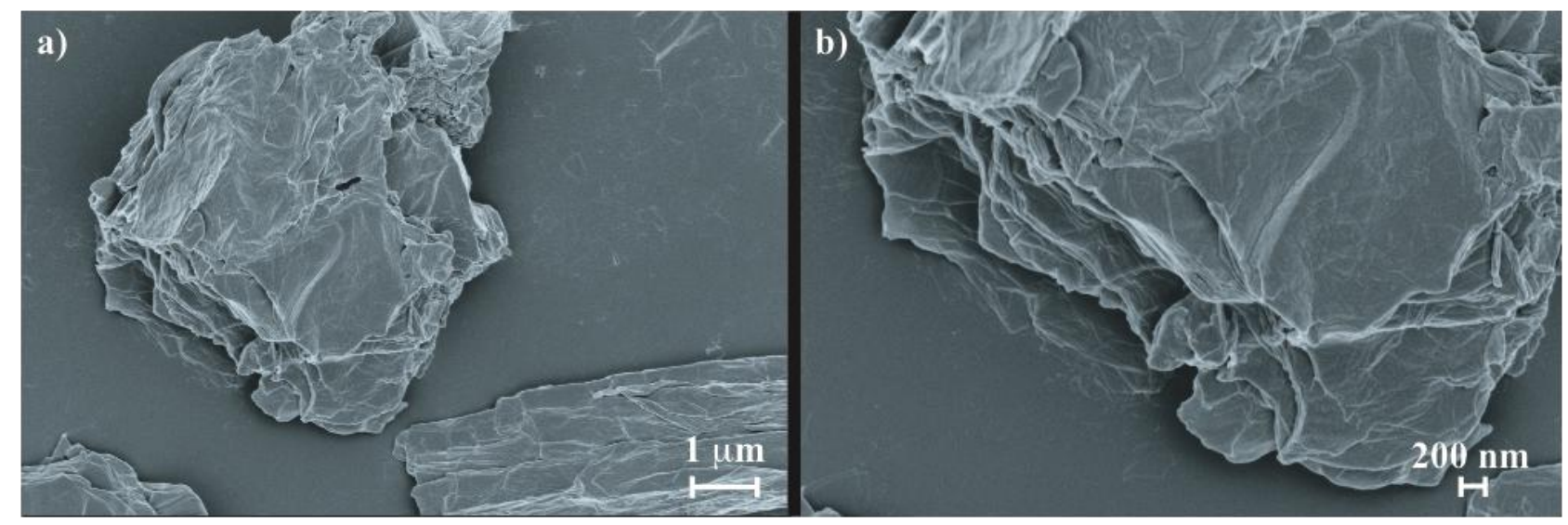

Figure 3. SEM images of GO powder

The FTIR spectra of GO is presented in Figure 4a). The results confirm the presence of main oxygencontaining groups, indicated by the absorption peaks at $3153 \mathrm{~cm}^{-1}(-\mathrm{OH}), 1716 \mathrm{~cm}^{-1}(-\mathrm{COOH}), 1334 \mathrm{~cm}^{-1}$, $1170 \mathrm{~cm}^{-1}$ and $1039 \mathrm{~cm}^{-1}(-\mathrm{O}-)$, and $974 \mathrm{~cm}^{-1}\left(-\mathrm{SO}_{3}\right)[1,17]$. 


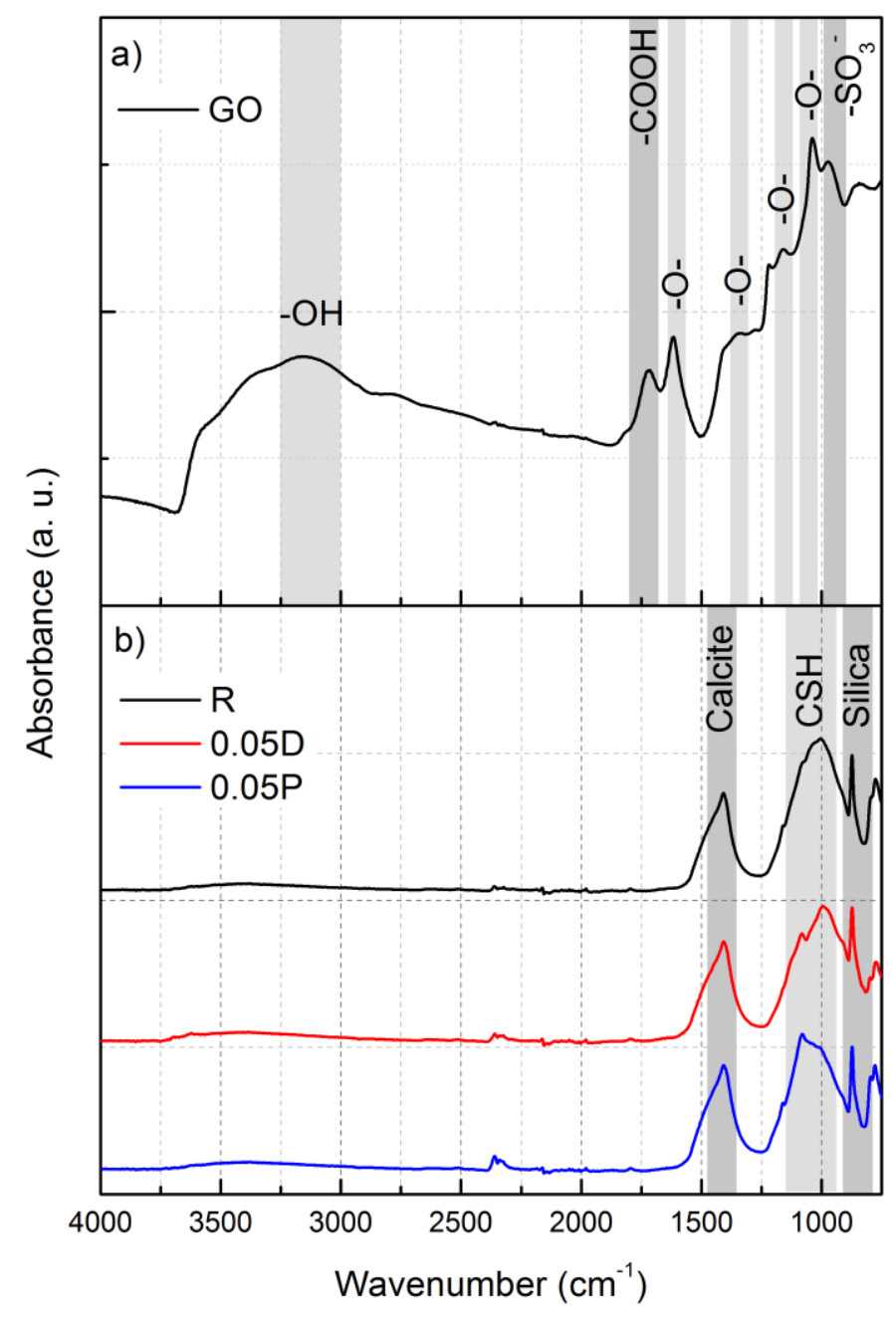

Figure 4. FTIR spectra of a) graphene oxide $(\mathrm{GO})$ produced and b) reference $(\mathrm{R})$, dispersed $(0.05 \mathrm{D})$ or powder $(0.05 \mathrm{P})$ GO mortars at 28 days

The FTIR spectra of reference mortar (R) and mortars incorporating 0.05 wt.\% dispersed GO (D) or powder $\mathrm{GO}(\mathrm{P})$ are shown in Figure 4b). For both mortars, with dispersed $\mathrm{GO}$ and powder $\mathrm{GO}$, the spectra are very similar to the reference mortar. Two distinct groups of bands can be identified: in the range $1280-1580 \mathrm{~cm}^{-1}$ and in $900-1120 \mathrm{~cm}^{-1}$. The first band is assigned to carbonate phases and the second band is assigned to CS-H phases. Starting with the identification of carbonates, the band of $1410 \mathrm{~cm}^{-1}$ can be attributed to calcite in all spectra. The C-S-H phases can be identified in bands around $970 \mathrm{~cm}^{-1}$ to the reference and $0.05 \mathrm{D}$ mortars, and in bands around $1070 \mathrm{~cm}^{-1}$ for the $0.05 \mathrm{P}$ mortar. Small variations in the range $900-1120 \mathrm{~cm}^{-1}$ confirm the presence of silica compounds in the sand [25]. Comparing the FTIR spectra of GO and the spectra shown in Figure $4 \mathrm{~b}$ ), it is concluded that is not possible to verify the presence of GO in produced mortars probably due to the small amounts of GO in the samples, when compared to the quantities of all other constituents. 
Figure 5a) show the XRD pattern of $\mathrm{GO}$, where the three main peaks of this material can be observed around $10^{\circ}, 26^{\circ}$ and $42^{\circ}(2 \theta)[1,26]$. The XRD diffractograms of reference mortar (R) and mortars incorporating 0.05 wt.\% of dispersed GO (D) or powder GO (P) are shown in Figure $5 \mathbf{b}$ ), wherein was detected calcite (C), belite $(\mathrm{L})$, quartz $(\mathrm{Q})$ and feldspar $(\mathrm{F})[25]$. Only in $\mathrm{R}$ mortar peaks were classified as unknown because it was not possible to identify the compound, concluding that there may have been some outside contamination that influenced the respective diffractogram.

The peaks identifying the GO are not visible in any of the XRD diffractograms, since the intensity of crystalline phase components of the mixture (lime and sand) is so high when compared to the amount of GO. Due to this, XRD measurement does not allow to understand if the incorporation of GO was effective.

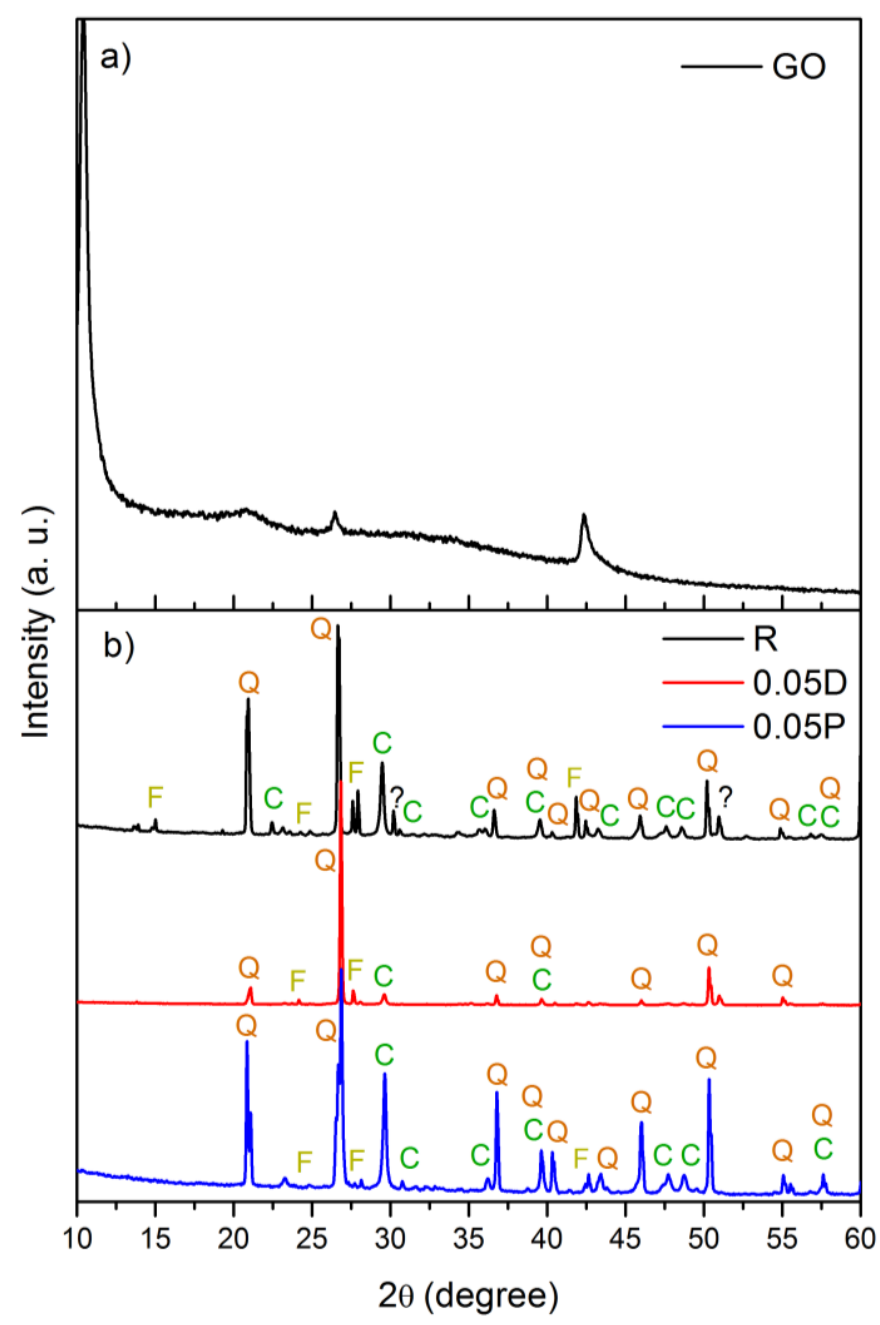

Figure 5. XRD diffractogram of a) graphene oxide $(G O)$ and b) reference $(R)$, dispersed (0.05D) or powder (0.05P) GO mortars at 28 days ( $\mathrm{C}$ - calcite; $\mathrm{F}$ - feldspar; $\mathrm{L}$ - belite; $\mathrm{Q}$ - quartz) 


\subsection{Fresh mortar consistency}

Mortars consistency determined by flow table test is presented in Table 3. It is an indirect way of assessing workability. The amount of water necessary to obtain adequate workability for application as rendering mortars was initially defined for the reference mortar. The addition of GO in NHL mortars does not have a significant influence on the mortars consistency.

In cement composites with the incorporation of GO, a more significant decrease of flow occurred. Pan et al. [4] produced Portland cement paste with 0.05 wt.\% of GO and observed that slump diameter is reduced by $41.7 \%$. The large surface area of GO sheets may be the cause for the respective decrease because when GO comes into contact with available water in fresh mixture wets its surface [4]. Babak et al. [7] observed that the increase of GO percentage into cement mortars while maintaining the water/cement ratio of matrix, diminished workability, maybe due to the presence of hydrophilic groups on the GO surfaces.

\subsection{Mechanical strength}

Results of flexural and compressive strength of mortars at 28 days are presented in Table 4. For mortars with 0.05 wt. \% and 0.1 wt.\% of dispersed GO the flexural strength was maintained and the compressive strength slightly increased relative to the reference mortar. For higher additions of dispersed GO in general the flexural and compressive strength slightly reduces. With powder GO the flexural strength of mortars slightly reduces while the compressive strength slightly increases.

Table 4. Flexural and compressive strength, open porosity and bulk density of mortars

\begin{tabular}{|c|c|c|c|c|c|}
\hline \multicolumn{2}{|c|}{ Mortar } & $\begin{array}{c}\text { Flexural } \\
\text { strength [MPa] }\end{array}$ & $\begin{array}{c}\text { Compressive } \\
\text { strength [MPa] }\end{array}$ & $\begin{array}{c}\text { Porosity } \\
{[\%]}\end{array}$ & $\begin{array}{c}\text { Bulk density } \\
{\left[\mathbf{k g} / \mathbf{m}^{3}\right]}\end{array}$ \\
\hline Without GO & $\mathrm{R}$ & $0.25 \pm 0.01$ & $0.56 \pm 0.04$ & $25.9 \pm 0.1$ & $1809 \pm 2$ \\
\hline \multirow{3}{*}{$\begin{array}{c}\text { Dispersed } \\
\text { GO }\end{array}$} & $0.05 \mathrm{D}$ & $0.24 \pm 0.04$ & $0.59 \pm 0.01$ & $25.7 \pm 0.4$ & $1791 \pm 8$ \\
\cline { 2 - 6 } & $0.1 \mathrm{D}$ & $0.25 \pm 0.04$ & $0.63 \pm 0.03$ & $26.1 \pm 0.1$ & $1781 \pm 7$ \\
\cline { 2 - 6 } & $0.5 \mathrm{D}$ & $0.19 \pm 0.04$ & $0.55 \pm 0.05$ & $27.0 \pm 0.0$ & $1784 \pm 11$ \\
\cline { 2 - 6 } & $1 \mathrm{D}$ & $0.22 \pm 0.02$ & $0.51 \pm 0.04$ & $26.8 \pm 0.2$ & $1784 \pm 10$ \\
\hline \multirow{2}{*}{$\begin{array}{c}\text { GO in } \\
\text { powder }\end{array}$} & $0.05 \mathrm{P}$ & $0.22 \pm 0.03$ & $0.59 \pm 0.05$ & $26.0 \pm 0.6$ & $1810 \pm 4$ \\
\cline { 2 - 6 } & $0.5 \mathrm{P}$ & $0.21 \pm 0.04$ & $0.57 \pm 0.04$ & $26.7 \pm 0.2$ & $1791 \pm 1$ \\
\hline
\end{tabular}

Minor variations were observed in the mechanical properties of mortars produced in this study maybe because NHL have smaller amounts of hydraulic components compared to a cement. According to Diekamp et al. [25], this may result in a weaker bond between the GO and the lime matrix. The type of sand, that is a major component of the mortars, may have contributed to these results because a poorly graded sand (with 
an almost vertical particle size distribution - Figure 1) was used. Grilo et al. [15] used the same binder in the production of NHL mortars but with a mixture of three washed siliceous sands. By comparing both reference mortars, it was found that higher mechanical properties were obtained. However, for application as rendering or plastering replacement mortars for historic buildings conservation and repair it is necessary to have low mechanical properties; so these results may be positive.

\subsection{Open porosity and bulk density}

The results obtained of open porosity and hardened bulk density are presented in Table 4 . It can be seen that with the addition of GO, dispersed or in powder, the open porosity tends to slightly increase. Moreover, with increasing dosages of $\mathrm{GO}$, hardened bulk density tends to slightly decrease.

As it has been seen before, with $0.05 \mathrm{wt} . \%$ and $0.1 \mathrm{wt} . \%$ of dispersed GO the flexural strength is maintained and the compressive strength slightly increased in comparison to the reference mortar. This increase, although slight, was not related to the open porosity or bulk density.

\subsection{Pore size distribution}

Figure 6 show the relationship between the cumulative intrusion pressure $(\mathrm{ml} / \mathrm{g})$ and pore diameter $(\mu \mathrm{m})$ of mortars produced with dispersed GO and powder GO. 


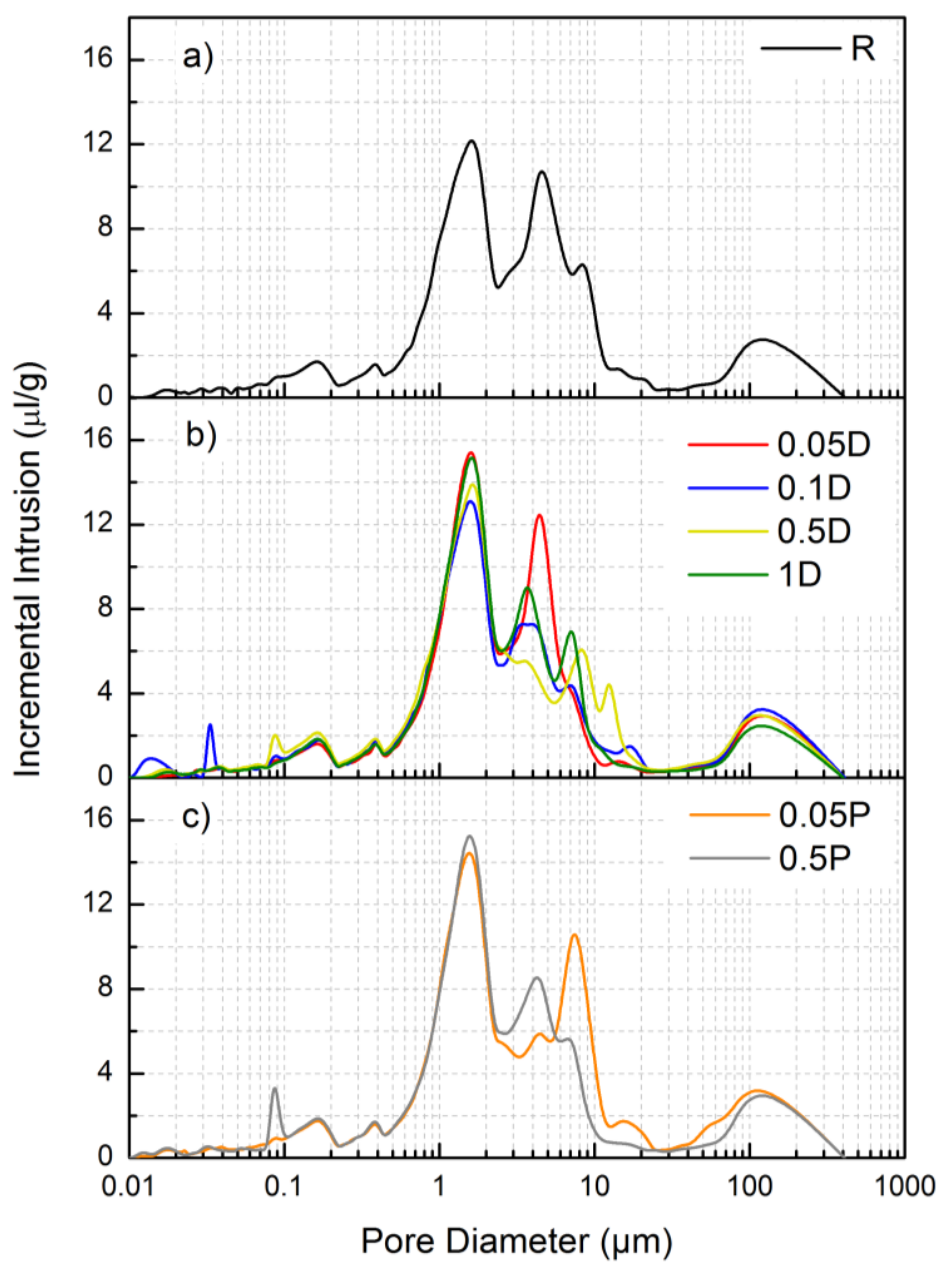

Figure 6. Mercury intrusion porosimetry of: a) reference mortar $(R)$; b) mortars with dispersed $\mathrm{GO}(0.05 \mathrm{D}, 0.1 \mathrm{D}, 0.5 \mathrm{D}$, $1 \mathrm{D})$; c) mortars with powder GO $(0.05 \mathrm{P}, 0.5 \mathrm{P})$

Figure 6b) shows little difference exists between the pore structure of the reference mortar and the mortar with GO addition; however, NHL-GO mortars present a higher intrusion at pore diameters around $1.5 \mu \mathrm{m}$ in comparison with the reference mortar, and a tendency to decrease the porosity around 2-4 $\mu \mathrm{m}$ of diameter when GO percentages increase, as well as porous in the range of 5-10 $\mu \mathrm{m}$ increase.

With respect to Figure $6 \mathrm{c}$ ) it can be seen that the addition of GO directly into powder also leads to little variation in the pore size distribution of the produced mortars. A similar trend is detected with this type of addition wherein an increase of pores of $2 \mu \mathrm{m}$ occurs with increasing dosage of GO powder. On the one hand there is a reduction of the amount of pores around $5 \mu \mathrm{m}$ in $0.05 \mathrm{P}$ mortar when compared to the reference mortar, and on the other, there is an increase of pores with about $7 \mu \mathrm{m}$. At the range of $4-7 \mu \mathrm{m}$ for $0.5 \mathrm{P}$ mortar a small decrease of pores' amount occurs. 


\subsection{Water absorption by capillarity}

The capillary water absorption curves are shown in Figure 7 and the values of capillary coefficient (CC) and the asymptotic value (AV) are presented in Table 5. It can be seen that $0.05 \mathrm{D}$ and $0.1 \mathrm{D}$ mortars are the ones that absorb water slightly faster than the reference mortar. According with the Table 5, a lower CC means that mortar initially absorbs water more slowly than reference mortar and a low AV means that absorbs less water in total. These results indicate that NHL-GO mortars have reduced capillary water absorption particularly for lower dosages of the dispersed GO.

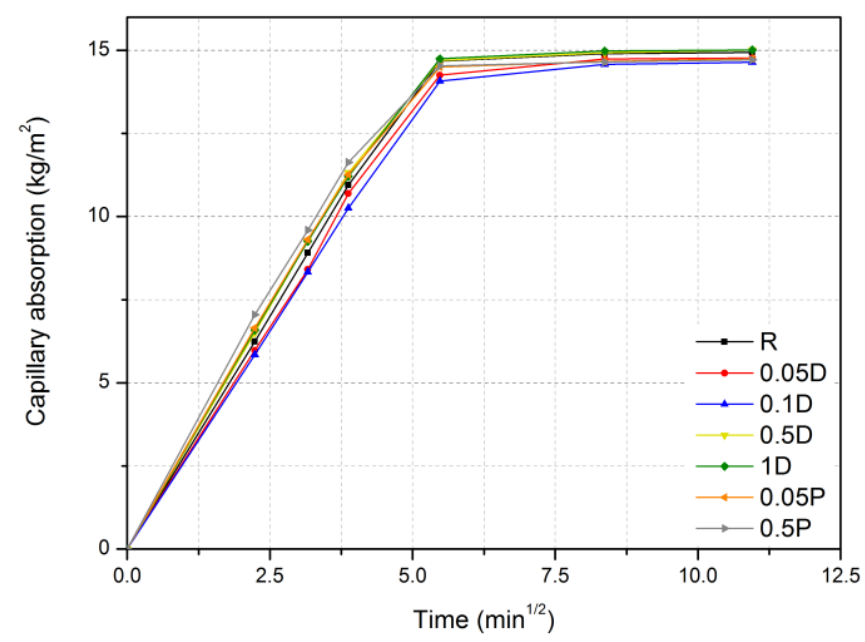

Figure 7. Capillary water absorption curves of mortars

Table 3. Capillary coefficient, asymptotic value, drying rates of phases 1 and 2 and drying index

\begin{tabular}{|c|c|c|c|c|c|}
\hline Mortar & $\begin{array}{c}\mathbf{C C} \\
{\left[\mathbf{k g} /\left(\mathbf{m}^{2} \cdot \mathbf{m i n}^{\mathbf{1} / 2}\right)\right]}\end{array}$ & $\begin{array}{c}\mathbf{A V} \\
{\left[\mathbf{k g} / \mathbf{m}^{2}\right]}\end{array}$ & $\begin{array}{c}\mathbf{D R} 1 \\
{\left[\mathbf{k g} /\left(\mathbf{m}^{2} \cdot \mathbf{h}\right)\right]}\end{array}$ & $\begin{array}{c}\mathbf{D R 2} \\
\left.\left[\mathbf{k g} / \mathbf{m}^{2} \cdot \mathbf{h}^{\mathbf{2}}\right)\right]\end{array}$ & $\begin{array}{c}\text { DI } \\
{[-]}\end{array}$ \\
\hline $\mathrm{R}$ & $2.71 \pm 0.03$ & $16.1 \pm 0.3$ & $0.13 \pm 0.01$ & $1.13 \pm 0.05$ & $0.19 \pm 0.00$ \\
\hline $0.05 \mathrm{D}$ & $2.63 \pm 0.02$ & $15.9 \pm 0.1$ & $0.13 \pm 0.01$ & $1.10 \pm 0.04$ & $0.19 \pm 0.00$ \\
\hline $0.1 \mathrm{D}$ & $2.59 \pm 0.07$ & $15.7 \pm 0.1$ & $0.16 \pm 0.01$ & $1.26 \pm 0.05$ & $0.17 \pm 0.01$ \\
\hline $0.5 \mathrm{D}$ & $2.72 \pm 0.02$ & $16.0 \pm 0.1$ & $0.14 \pm 0.01$ & $1.16 \pm 0.06$ & $0.18 \pm 0.01$ \\
\hline $1 \mathrm{D}$ & $2.72 \pm 0.01$ & $16.3 \pm 0.3$ & $0.16 \pm 0.02$ & $1.30 \pm 0.06$ & $0.17 \pm 0.01$ \\
\hline $0.05 \mathrm{P}$ & $2.68 \pm 0.01$ & $16.0 \pm 0.1$ & $0.17 \pm 0.01$ & $1.31 \pm 0.09$ & $0.17 \pm 0.01$ \\
\hline $0.5 \mathrm{P}$ & $2.70 \pm 0.01$ & $15.7 \pm 0.1$ & $0.17 \pm 0.01$ & $1.33 \pm 0.04$ & $0.17 \pm 0.00$ \\
\hline
\end{tabular}

CC - capillary coefficient; AV- asymptotic value of capillary absorption; DR1 and DR2 - drying rates of the $1^{\text {st }}$ and $2^{\text {nd }}$ drying phases; $\mathrm{DI}$ - drying index

Mohammed et al. [2] have shown that mortars incorporating 0.03 wt.\% of GO have a water absorption decrease compared to reference mortar attributing that to the increased amount of smaller pores and 
reduction of capillary porosity with the addition of GO, according to their pore size distribution results. The researchers suggest that GO addition on cement composites can improve its resistance to aggressive elements through the interconnection of the GO structure with the cement matrix, which gives rise to a strong barrier and allows to reduce the penetration of aggressive agents. Since the MIP results with NHL-GO mortars mainly show enhanced nanoporosity, that may justify the positive effect of GO on capillary absorption.

\subsection{Drying capacity}

No significant differences were observed in the drying curves to determine the drying rate corresponding to the first drying phase (DR1) of GO mortars (Table 5); for that reason, those drying curves are not presented. Nevertheless the first phase of drying presents a tendency to a very slight increase with a addition of GO. The drying curves to obtain the drying rate corresponding to the second drying phase are shown in Figure 8 and the respective values of DR2 and the drying index (DI) are presented in Table 5.

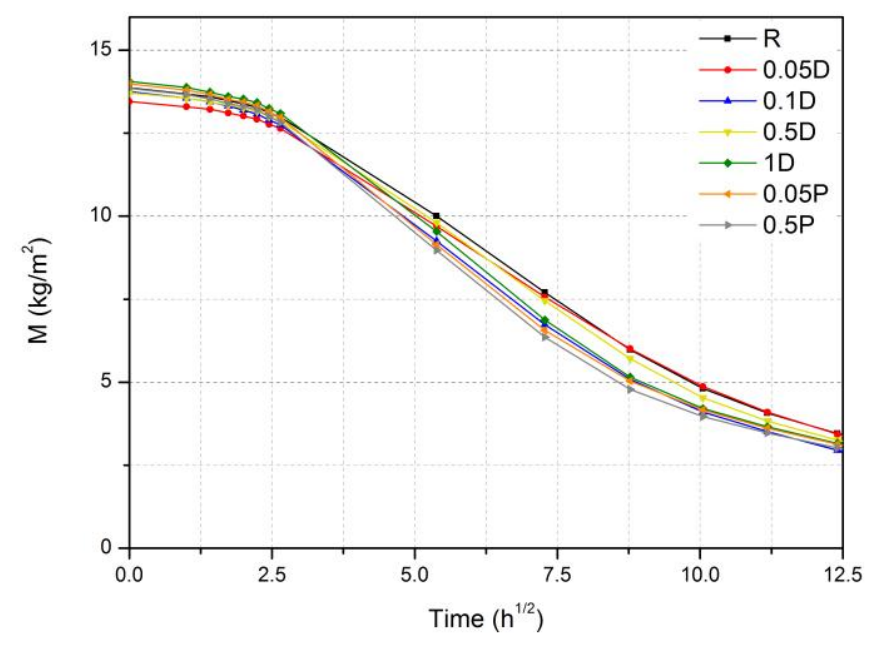

Figure 8. Drying curves and linear segments corresponding to the second drying phase of mortars

It is observed that increased dosages of GO, dispersed or on powder, lead to a faster drying in the second phase in comparison with the reference mortar. Based on Table 5, only 0.05D mortar maintains the calculated drying parameters; all the other mortars have drying rates slightly above and a DI slightly below than the reference mortar, which is positive. Having a higher drying rate means that the mortar has a faster drying in that phase and a lower DI indicates a globally easier drying behaviour. Therefore, all the mortars with more than $0.05 \%$ GO present less resistance to the drying process in comparison to the reference mortar.

In this case, the best results are observed for the mortars with dosages greater than $0.1 \mathrm{wt} \%$ dispersed or on powder GO. The results are consistent with the open porosity because higher dosages of dispersed or powder GO lead to a higher porosity, thereby facilitating the drying process. 


\section{Conclusions}

Natural hydraulic lime mortars incorporating GO sheets were produced and the influence of GO, dispersed or in powder, on the fresh mortars consistency, mechanical properties, capillary water absorption, drying and microstructure of hardened mortars were investigated. In general, more positive results were obtained for mortars containing the water dispersed GO, indicating a better incorporation of GO sheets in comparison with GO added in powder. Nevertheless, mineralogical testing did not identify the GO compounds, perhaps because of the low GO content.

GO addition in low weight percentages of $0.05 \mathrm{wt} . \%$ and $0.1 \mathrm{wt} . \%$ lead to a slight improvement of mechanical characteristics compared to reference mortars. Also, mortars incorporating 0.1 wt. $\%$ dispersed GO provided positive results for water behaviour, in liquid or vapour, as the capillary water absorption is slower and in less quantity and the drying is faster.

Although the overall enhancement is not remarkable, this study gives a good indication that formulated NHL mortars may be optimized in terms of durability in humid environments by the addition of GO, varying the formulation and/or the type of sand. The fact that mechanical strength does not change much allows to maintain compatibility with historic materials, which may be of great interest for rendering, plastering or repointing mortars for conservation or rehabilitation interventions on historic buildings.

\section{Acknowledgment}

The authors would like to thank Professor Dr. Jonathan Phillips (Naval Postgraduate School) for reviewing the text and want to acknowledge the financial support of European Commission under the projects H2020-ICT2014-1, RIA, TransFlexTeg-645241 and ERC-CoG-2014, ChapTherPV-647596, and FEDER through the COMPETE 2020 Program and National Funds of FCT - Portuguese Foundation for Science and Technology under the projects UID/CTM/50025/2013 and PTDC/EPH-PAT/4684/2014 (DB-HERITAGE) and PhD grant SFRH/BD/113263/2015 of Paulo Duarte.

\section{References}

[1] S. Lv, S. Ting, J. Liu, Q. Zhou, Use of graphene oxide nanosheets to regulate the microstructure of hardened cement paste to increase its strength and toughness, CrystEngComm 16 (2014) 8508-8516. doi:10.1039/c4ce00684d. 
[2] A. Mohammed, J.G. Sanjayan, W.H. Duan, A. Nazari, Incorporating graphene oxide in cement composites: A study of transport properties, Construction and Building Materials 84 (2015) 341-347. doi:10.1016/j.conbuildmat.2015.01.083.

[3] Y. Shang, D. Zhang, C. Yang, Y. Liu, Y. Liu, Effect of graphene oxide on the rheological properties of cement pastes, Construction and Building Materials $96 \quad$ (2015) 20-28. doi:10.1016/j.conbuildmat.2015.07.181.

[4] Z. Pan, L. Heb, L. Qiu, A.H. Korayem, G. Li, J.W. Zhu, et al., Mechanical properties and microstructure of a graphene oxide-cement composite, Cement and Concrete Composites 58 (2015) 140-147. doi:10.1016/j.cemconcomp.2015.02.001.

[5] A. Cwirzen, K. Habermehl-Cwirzen, V. Penttala, Surface decoration of carbon nanotubes and mechanical properties of cement/carbon nanotube composites, Advances in Cement Research 20 (2008) 65-73. doi:10.1680/adcr.2008.20.2.65.

[6] S. Xu, J. Liu, Q. Li, Mechanical properties and microstructure of multi-walled carbon nanotube-reinforced cement paste, Construction and Building Materials $76 \quad$ (2015) 16-23. doi:10.1016/j.conbuildmat.2014.11.049.

[7] F. Babak, H. Abolfazl, R. Alimorad, G. Parviz, Preparation and mechanical properties of graphene oxide: cement nanocomposites, The Scientific World Journal (2014) Article ID 276326. doi:10.1155/2014/276323.

[8] S. Lv, Y. Ma, C. Qiu, T. Sun, J. Liu, Q. Zhou, Effect of graphene oxide nanosheets of microstructure and mechanical properties of cement composites, Construction and Building Materials 49 (2013) 121-127. doi:10.1016/j.conbuildmat.2013.08.022.

[9] G.Y. Li, P.M. Wang, X. Zhao, Mechanical behavior and microstructure of cement composites incorporating surface-treated multi-walled carbon nanotubes, Carbon $43 \quad$ (2005) 1239-1245. doi:10.1016/j.carbon.2004.12.017.

[10] O. Galao, E. Zornoza, F.J. Baeza, A. Bernabeu, P. Garcés, Effect of carbon nanofiber addition in the machanical properties and durability of cementitious materials, Materiales de Construcción 62 (2012) 343357. doi:10.3989/mc.2012.01211.

[11] Q. Wang, J. Wang, C. Lu, B. Liu, K. Zhang, C. Li, Influence of graphene oxide additions on the microstructure and mechanical strength of cement, New Carbon Materials 30 (2015) 349-356. doi:10.1016/S1872-5805(15)60194-9.

[12] J. Chen, D. Zhao, H. Ge, J. Wang, Graphene oxide-deposited carbon fiber/cement composites for electromagnetic interference shielding application, Construction and Building Materials 84 (2015) 66-72. doi:10.1016/j.conbuildmat.2015.03.050. 
[13] CEN, EN 459-1:2010. Building lime. Part 1: Definitions, specifications and conformity criteria, European Committee of Standardization, Brussels, 2010.

[14] P. Faria, R. Piteira, Natural hydraulic lime (NHL3.5) mortars with scrap tire rubber. ALITinform International Analytical Review 6 (41) (2015) 62-72.

[15] J. Grilo, P. Faria, R. Veiga, A. Santos Silva, V. Silva, A. Velosa, New Natural Hydraulic Lime mortars Physical and microstructural properties in different curing conditions, Construction and Building Materials 54 (2014) 378-384. doi:10.1016/j.conbuildmat.2013.12.078.

[16] L. Baltazar, F. Henriques, F. Jorne, T. Cidade, Combined effect of superplasticizer, silica fume and temperature in the performance of natural hydraulic lime grouts. Construction and Building Materials 50 (2014) 584-597. http://dx.doi.org/10.1016/j.conbuildmat.2013.10.005

[17] L. Shahriary, A.A. Athawale, Graphene Oxide Synthesized by using Modified Hummers Approach, International Journal of Renewable Energy and Environmental Engineering 02 (2014) 58-63.

[18] CEN, EN 1015-2:1998. Methods of test for mortar for masonry. Part 2: Bulk sampling of mortars and preparation of test mortars, European Committee for Standardization, Brussels, 1998.

[19] CEN, EN 1015-3:1999. Methods of test for mortar for masonry. Part 3: Determination of consistence of fresh mortar (by flow table), European Committee for Standardization, Brussels, 1999.

[20] CEN, EN 1015-11:1999. Methods of test for mortar for masonry. Part 11: Determination of flexural and compressive strength of hardened mortar, European Committee for Standardization, Brussels, 1999.

[21] CEN, EN 1936:2008. Natural stone test methods - Determination of real density and apparent density, and of total and open porosity, European Committee for Standardization, Brussels, 2008.

[22] CEN, EN 1015-18:2002. Methods of test for mortar for masonry. Part 18: Determination of water absorption coefficient due to capillary action of hardened mortar, European Committee for Standardization, Brussels, 2002.

[23] CEN, EN 15801:2009. Conservation of cultural property. Test methods: Determination of water absorption by capillarity, European Committee for Standardization, Brussels, 2009.

[24] CEN, EN 16322:2013. Conservation of Cultural Heritage. Test methods: Determination of drying properties, European Committee for Standardization, Brussels, 2013.

[25] A. Diekamp, R. Stalder, J. Konzett, P.W. Mirwald, Lime Mortar with Natural Hydraulic Components: Characterisation of Reaction Rims with FTIR Imaging in ATR-Mode, Historic Mortars 7 (2012) 105-113. doi:10.1007/978-94-007-4635-0_8. 
[26] C. Zhang, X. Zhu, Z. Wang, P. Sun, Y. Ren, J. Zhu, et al., Facile synthesis and strongly microstructuredependent electrochemical properties of graphene/manganese dioxide composites for supercapacitors, Nanoscale Research Letters 9 (2014) 490. doi:10.1186/1556-276X-9-490. 